\title{
METHODS FOR INTRODUCING A NEW INTERLOCKING SYSTEM IN OMIYA STATION, JAPAN
}

\author{
KOJI SUGIURA, TAKASHI KAWANO, KATSUYA KATO, HIDEKI KOMUKAI \& YUSUKE TAKANO \\ Electrical \& Signal Network System Department, East Japan Railway Company, Japan
}

\begin{abstract}
East Japan Railway Company has been going forward with computer-based interlocking migration strategies. More than 20 have been replaced each year. One of the major issues is how to efficiently test the current systems in the limited maintenance time whilst staying within the deadline as scheduled. Omiya station is one of the largest and most significant hub railway stations in the company - where Tohoku line, Saikyo line, and Takasaki line converge. We replaced this station's interlocking system in January 2017, introducing a system which was based on both the new IP control technology using optical cables and the conventional technology using copper cables. As the system controls a large number of signalling devices, we must complete numerous onsite tests in a regular maintenance time of about two hours per day. In this paper, we will present the station's system structure and the changeover method we applied in Omiya station using both switching relays and IP controlled devices. We tested the system onsite and changed it successfully without causing any suspension of the train operations.
\end{abstract}

Keywords: computer-based interlocking, IP control, optical fiber, plug-in relay, overlap track circuit.

\section{INTRODUCTION}

East Japan Railway Company is one of the passenger railway companies in Japan which operates trains in the east side of the country. We operate about a 7,500 km line which includes Shinkansen line of 1,200 km. Table 1 shows the data of our company and Fig. 1 represents the routes we operate. We have 1,700 stations and 1,000 interlocking systems, of which around 600 systems are computer-based and the others 400 are relay and wiring-based systems. Omiya station is located $30 \mathrm{~km}$ north of the Tokyo station. It is an important hub railway station where Tohoku-line, Saikyo-line, and Takasaki-line trains meet, and 252,000 passengers use this station per day. There is one of the largest computer-based interlocking systems in our company, which manages a large number of signalling devices, and as it has been used for more than 20 years. We replaced the system with a new one including novel IP control devices.

\section{THE SYSTEM STRUCTURE OF OMIYA STATION}

The interlocking system at Omiya station manages 128 routes of wayside signals, 64 point machines, 163 transponders for ATP, and 7 level crossings. The system also manages the other devices like the warning system of approaching trains for maintenance workers which uses the train information in the interlocking. The system is also connected with 118 track circuits to detect the train position and with the operation control center to receive railway timetables to set the route automatically. We have also developed and introduced to this station the novel wayside signals in which Optical Network Terminal (ONT) are embedded and controlled by IP-based optical networking technology. We introduced this IP based devices in all 67 signals in the northern part of the station, as shown in Fig. 3. The rest signals located in the south half are left to be conventional signalling devices controlled through copper cables. This is because we have a plan to change the track layout of this area to optimize the train traffic at the station. We assessed that it is more reasonable to replace these devices with new ones at the same time as we change the track configuration. 
Table 1: The data of East Japan Railway Company.

\begin{tabular}{|l|c|}
\hline Railway length & $7,458 \mathrm{~km}$ \\
\hline Number of stations & 1,665 \\
\hline Number of interlocking systems based on computer & 598 \\
\hline Number of interlocking systems based on relay and wiring & 383 \\
\hline
\end{tabular}

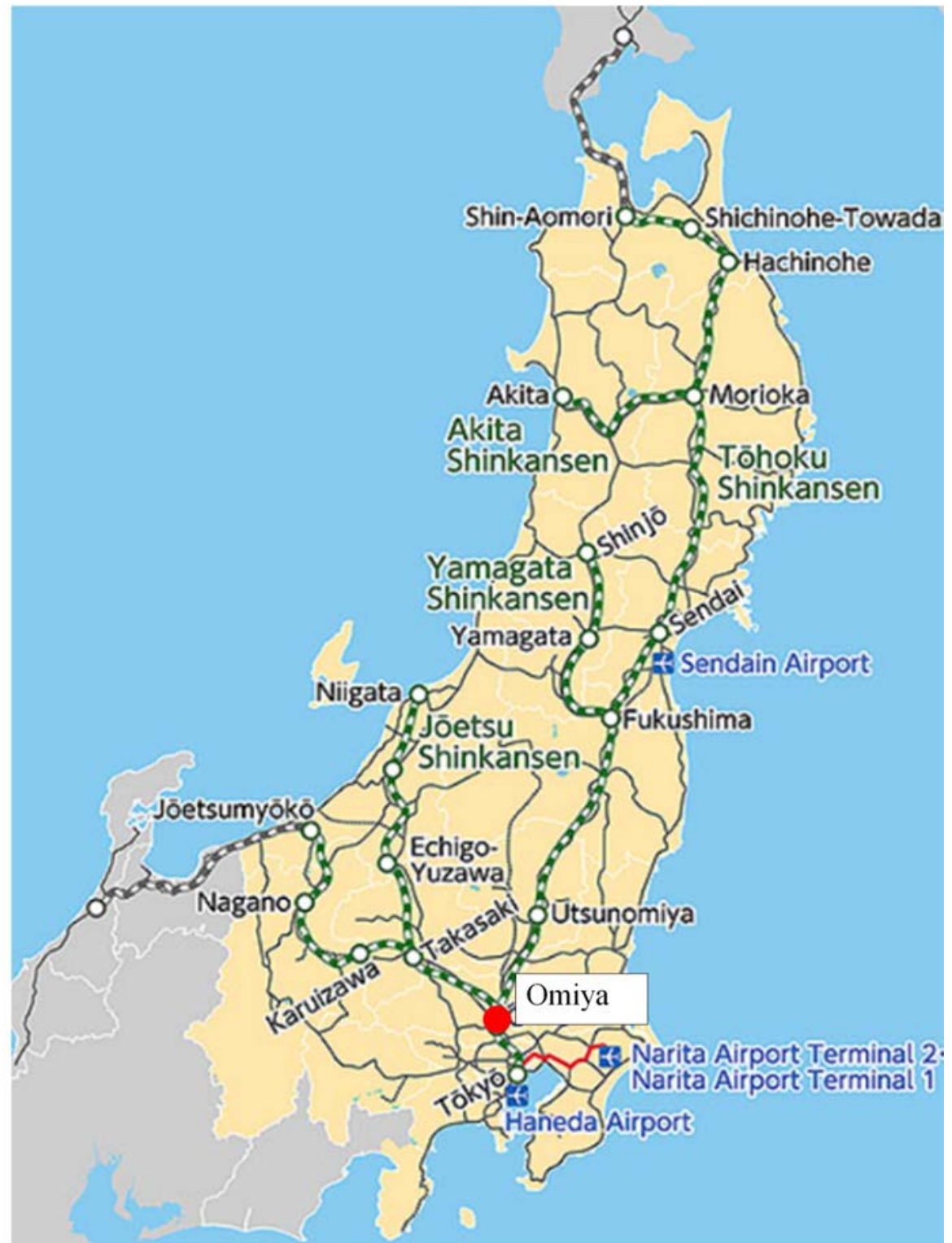

Figure 1: Operation lines of East Japan Railway Company and the location of Omiya station. 


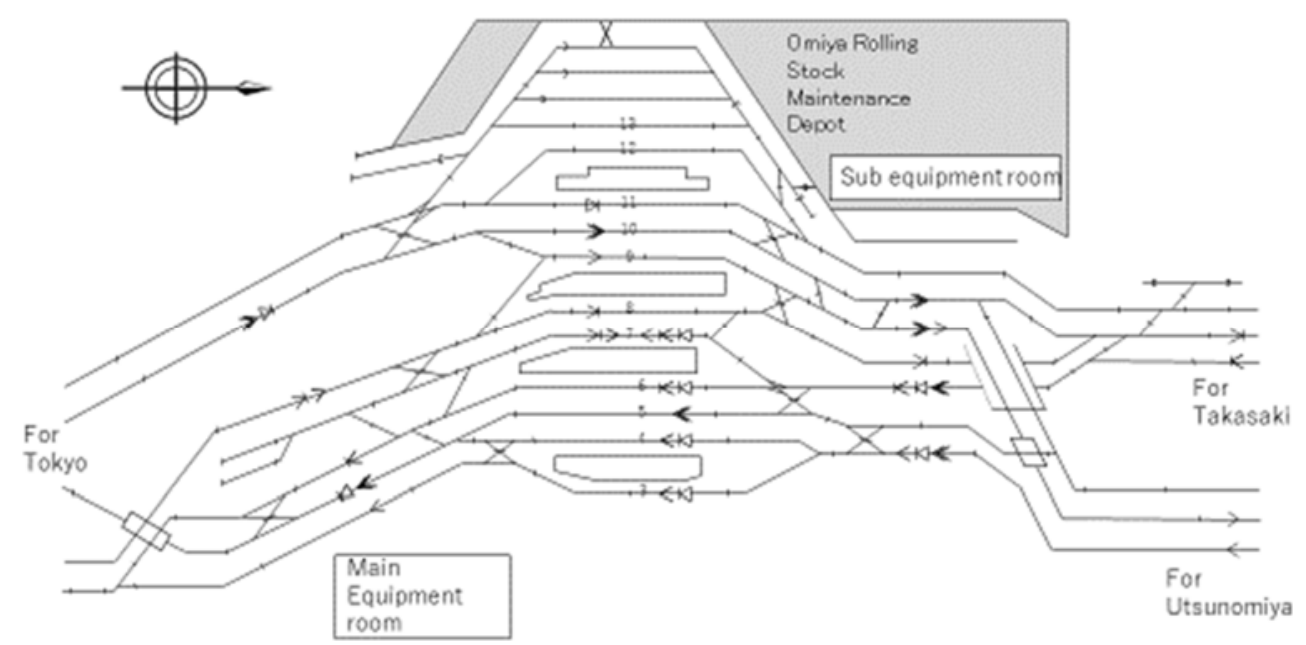

Figure 2: The track layout of Omiya station.

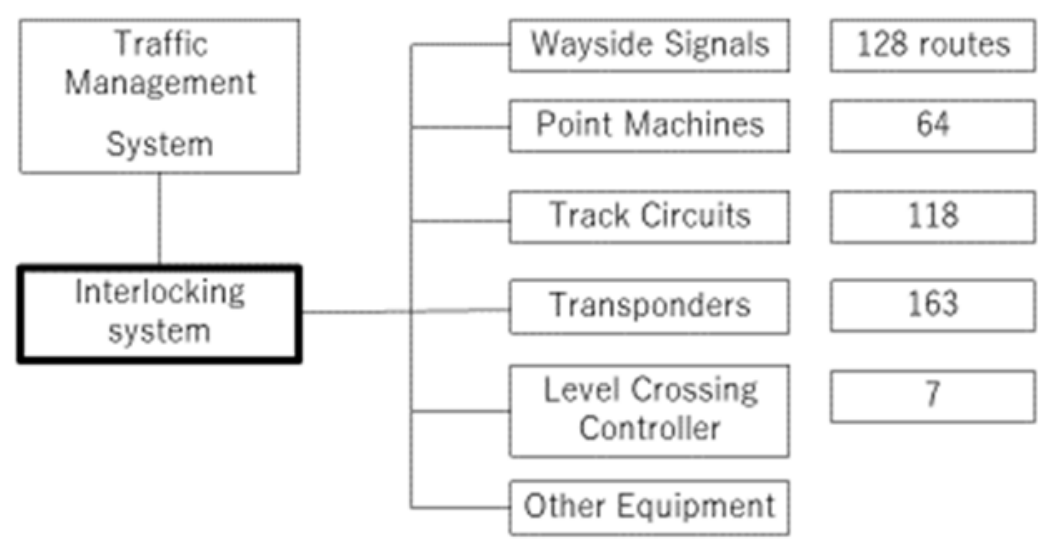

Figure 3: The system structure of signalling system in Omiya station.

The difference between the system structures of IP controlled signalling system and the conventional signalling system is shown in Fig. 4. The electronic drivers named Field Controllers (FC) including ONTs are embedded in these novel signalling devices, so that the interlocking system can control them through only a pair of optical fibers. The FCs in each signalling device are duplicated to implement the redundancy. The current signallimg devices are controlled by copper cables in which more pairs of core wires are needed according to the devices' requirement, which depends on numbers of the lights or the route directions they indicate. Introducing these new devices enable us to reduce the volume of laying cables and cable troughs near the trackside. At Omiya station, we introduced both types of signalling devices because of the future re-engineering of the track configuration. 


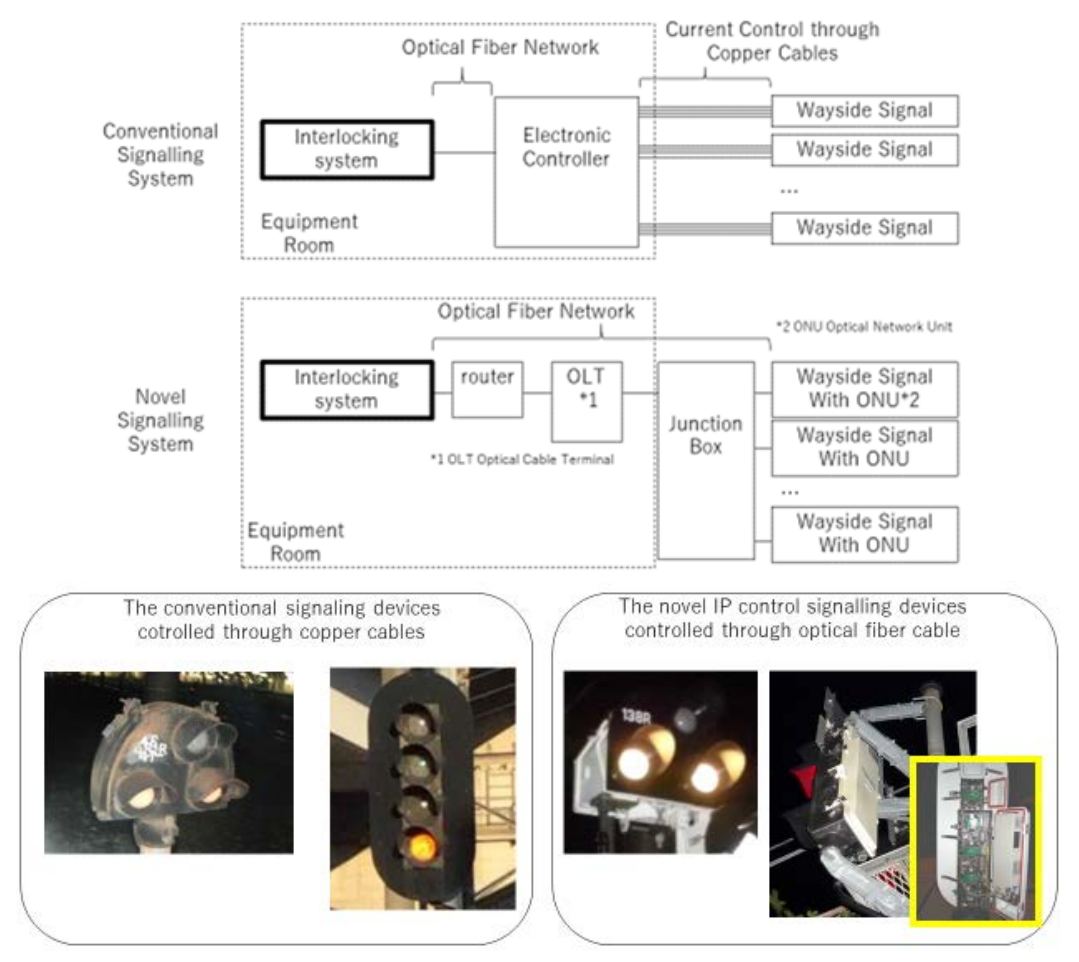

Figure 4: The structure and pictures of the conventional signalling system and the novel signalling system.

Our company has introduced the electronic interlocking equipment which consists of failsafe hardware, common interlocking software, and a specific interlocking data of the station. The specific data are generated automatically from interlocking tables and identification tables which represent the relationships among the signalling devices and the other parameters for automatic route settings, e.g. the timing of the route setting and the maximum number of point machines allowed to switch at once. This software generating system is named IDS, abbreviation of Interlocking Data generation System [1]. IDS generate the specific interlocking data of a station, and the interlocking system can perform on the common interlocking software with the generated dataset. IDS is reported to have highly improved safety level of the interlocking system by Railway Technical Research Institute, RTRI. We also developed the IQS, abbreviation of Interlocking Quality assurance System [2]. IQS checks the interlocking system automatically by installing these tables into the system and connecting it to the interlocking that is going to be checked. As the possibility of human error is eliminated by the examination with IQS, the results ensure the safety behavior of the interlocking. We show the outline of this process in Fig. 5.

\section{THE SYSTEM CHANGING METHOD APPLIED IN THIS PROJECT}

After the acceptance testing, the interlocking is installed into the equipment rooms at the station. Then, the electrical contractor connects all the track side signalling devices to the 


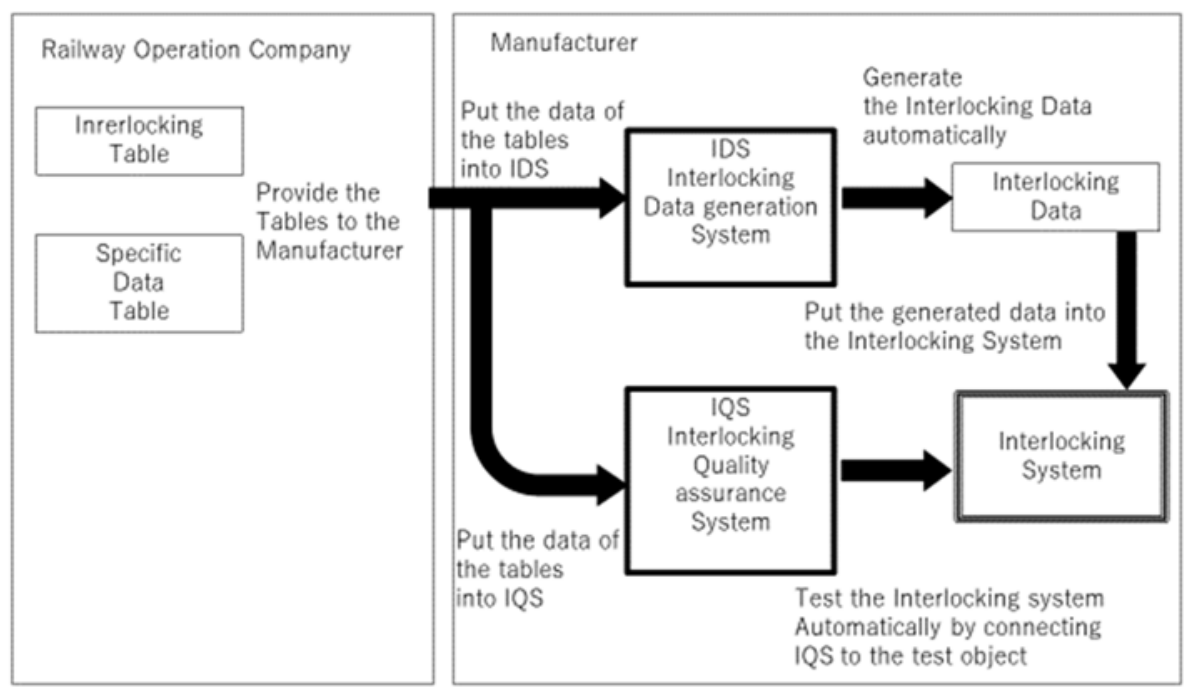

Figure 5: The process of developing Interlocking system developing IDS and IQS.

new system with cables. To confirm the right connections between the devices and the interlocking system that ensure the safety train movement, the onsite testing is inevitable. As the daily maintenance time is about 2 hours at Omiya station, we must implement the changing method of the connection between the devices and the interlockings rapidly from the operating system to the new system under examination. We applied three major techniques at Omiya station. They are the relay application, the IP based technique and the overlapping the track circuit signals.

\subsection{The relay application}

The relay application is conventional one which is using signalling plug-in relays. Fig. 6 shows the changeover method of devices which are controlled through metal cables. The current system is connected to the terminals linked to the back contact and the new system is connected the front contact of the changeover relays respectively. The devices are connected to the terminal linked to the armature contacts. As the current system is connected to the back contacts which are close when they are de-energized, the devices are kept connected to the current system even if some failure occurs to the power supply devices for the relay equipment.

The changeover relay has 11 sets of contacts, and usually use one set for a lamp circuit to indicate the relay condition to the indictor in the equipment room. The supervisors of the onsite testing can make sure that the condition of all relays is recovered correctly before the train operations.

\subsection{The IP based technique}

We introduced 67 novel wayside signals based on IP technology as mentioned above. These devices should be connected to the previous system during the operation time and switched 

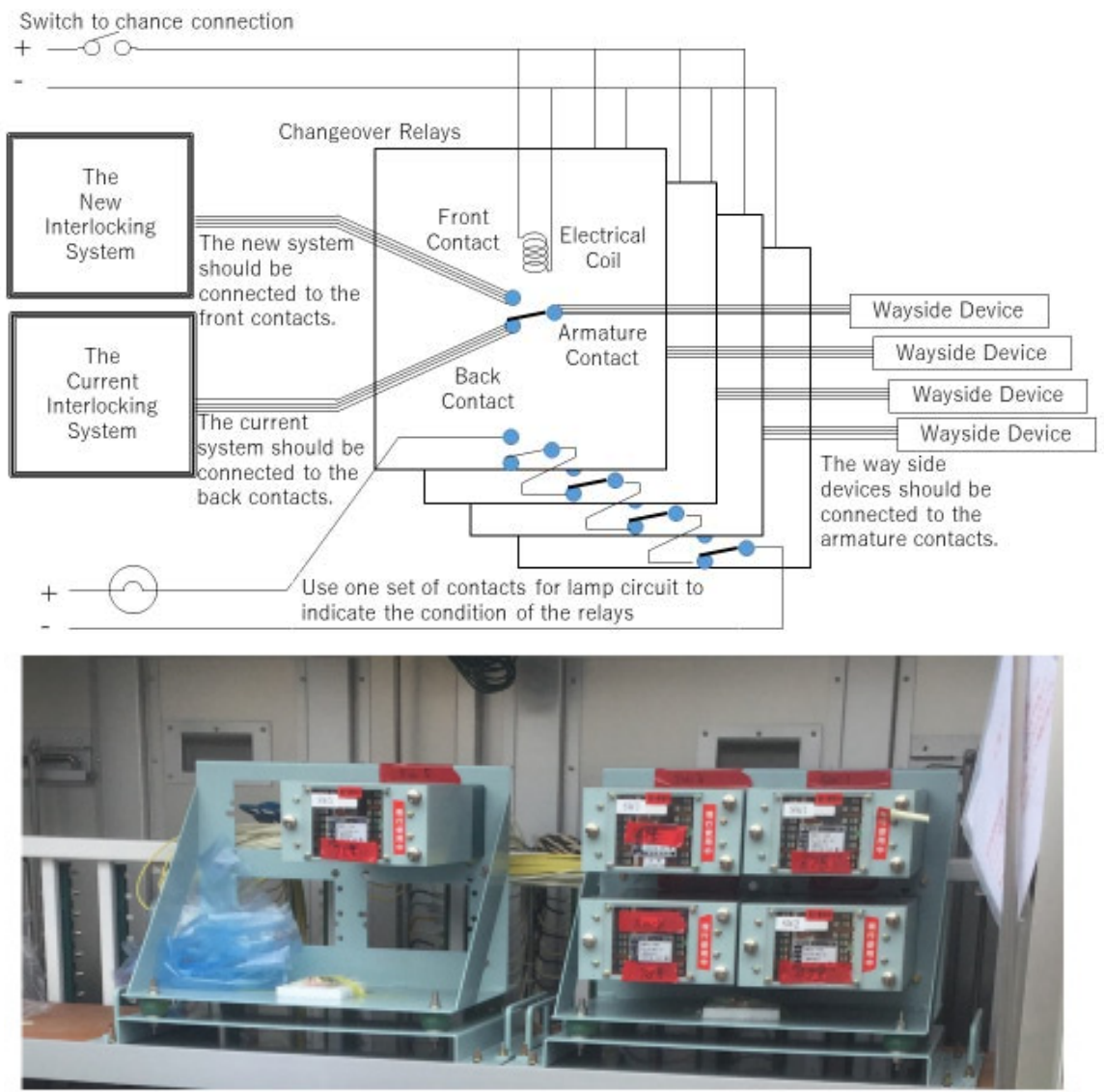

Figure 6: The changeover method using plug-in relays and a picture of the relays.

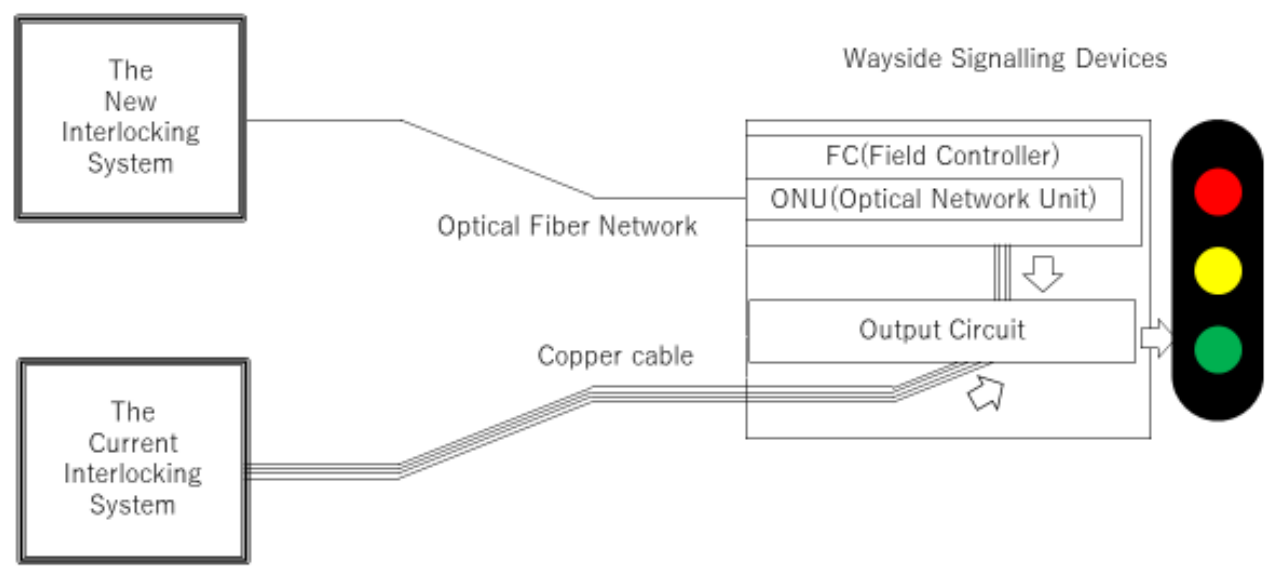

Figure 7: The changeover method IP based wayside signal. 


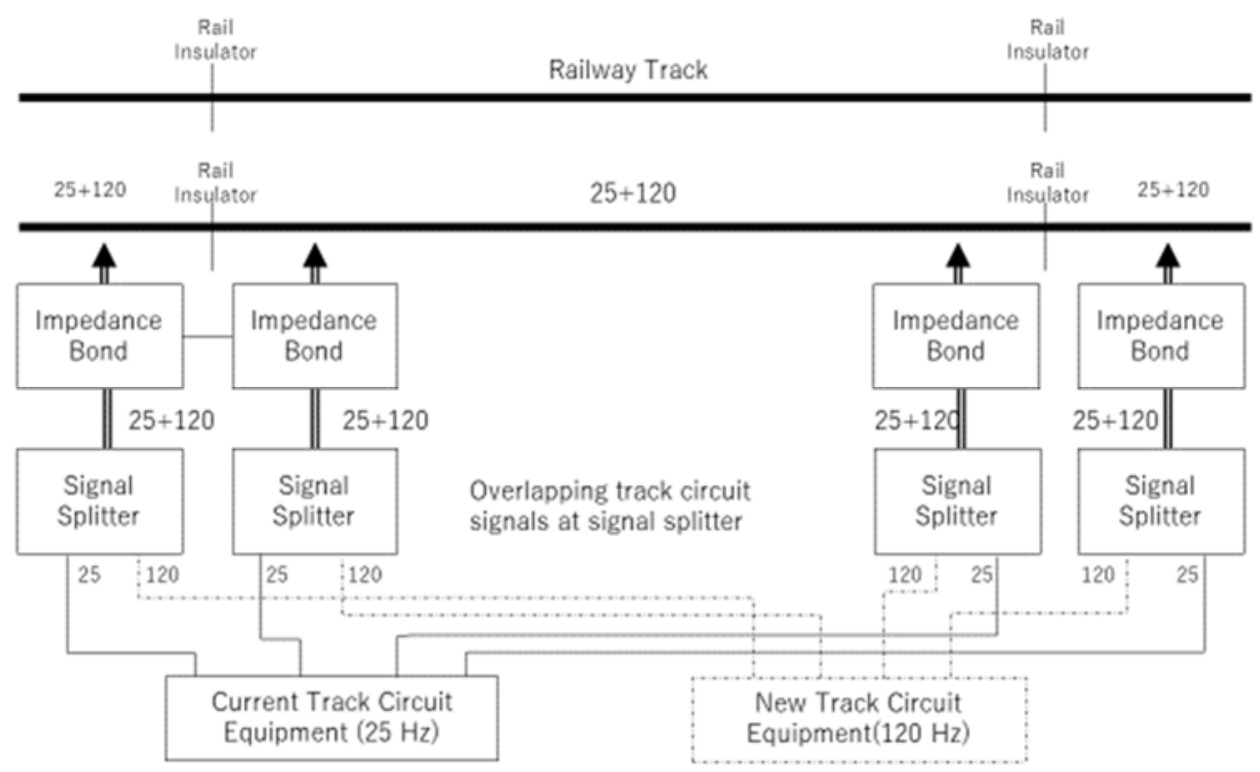

Figure 8: The structure of the overlapping method for track circuit equipment.

to the new system during the maintenance time for the testing as other conventional devices. These signalling devices includes components which make them possible to connect with both a conventional interlocking system and to a new IP based system. These components can work at the same time so that adding switching elements outside for change over is not necessary. Instead of changing the switching elements, we just turn on the system to be connect with the devices and off the system which is not required.

\subsection{The overlapping the track circuit signals}

We introduced the signal splitter which is composed with band-pass filters in order to overlap the two track circuit signals simultaneously in the same track. The splitter can pass two frequencies of signals and it can split and overlap two signals on the tracks. For implementing this overlapping method, we chose a different frequency of the track circuit signal for the new equipment compared with the current signal. Fig. 8 shows the structure of track circuits with overlapping method.

By using this method, both track circuit equipment can detect the occupied and unoccupied tracks simultaneously so that this makes the train operation and the track circuit testing possible at the same time. It also enables us to check the behavior of the new interlocking system and the traffic management system according to the actual train movement as well.

\section{CONCLUSIONS}

In this paper, we explained three replacing methods of the interlocking system applied at Omiya station. The first one is using plug-in relays, which can be applied for devices controlled over copper cables. This method is widely used in our company for replacement of various kind of signalling equipment as this can be applied to all devices connected and 
controlled through copper cables. The second one is for the new signalling devices depend on the IP control technology and optical fiber cables. These devices include the components which make it possible to connect with both the current system and the replacing one so that we need not prepare any elements outside the devices to switch the connection. The last one is the track circuit signal overlapping method. This method enables us to operate the current system and to test the new equipment simultaneously. Due to these methods, the system replacing project at Omiya station progressed as scheduled and we exchanged the system in Jan. 2017 without any trouble or suspension in train operation.

\section{REFERENCES}

[1] Iwamoto, T. et al., The automatic data generating system for interlocking and traffic management system. Proceedings of the 31st Japan Railway Engineers' Association Conference, pp. 191-194, 1994 (Japanese).

[2] Ishihara, S. et al., The automatic testing system for interlocking system. Proceedings of the 31st Japan Railway Engineers' Association Conference, pp. 375-378, 1994 (Japanese).

[3] Kunifuji, T. et al., A railway signal control system by optical LAN and design simplification. Journal of Networks, 3(7), Jul. 2008. 